Original Article

\title{
On balancing supply chain efficiency and environmental impacts: An eco-DEA model applied to the dry port sector of India
}

\author{
Hercules Haralambides and Girish Gujar \\ Centre for Maritime Economics and Logistics, Erasmus University Rotterdam, \\ the Netherlands. \\ E-mail: harambides@ese.eur.nl
}

\begin{abstract}
Indian dry ports (inland cargo-consolidation and distribution centres) are expected to play a pivotal role in connecting the North Indian heartland with the gateway seaports of Mundra, JNPT and Chennai. However, in this process, dry ports contribute considerably to the vexing problem of atmospheric pollution because of the ensuing road and rail transportation. There is a considerable body of research on the socially undesirable side effects of production, for instance in sectors such as manufacturing and transport. In spite of this, the standard methods so far employed in the analysis of port efficiency and productivity, notably data envelopment analysis (DEA), have failed to address and internalize the economic ramifications of transport externalities. In this article, a comparative study of the typical DEA models is undertaken, in an effort to illustrate the problem at hand. A new eco-DEA model is proposed that simultaneously evaluates both the undesirable and the desirable outputs of port service production. The model is applied to evaluate dry port efficiency, while taking into account the $\mathrm{CO}_{2}$ emissions caused by the transport of containers from dry ports, located in the North Capital Region of India, to the various gateway (coastal) ports. The results reveal that efficiency evaluations are significantly altered once environmental aspects are factored in to the model. The methodology proposed here can be easily transferred to any other industrial sector where environmental concerns are becoming an issue.
\end{abstract}

Maritime Economics \& Logistics (2012) 14, 122-137. doi:10.1057/mel.2011.19

Keywords: dry ports; data envelopment analysis; transport externalities; India

(C) 2012 Macmillan Publishers Ltd. 1479-2931 Maritime Economics \& Logistics Vol. 14, 1, 122-137 www.palgrave-journals.com/mel/ 


\section{Introduction}

As a result of significant policy changes by the government of India, whereby the private sector is now allowed to invest in the dry port and rail transport industry, the dry port sector is currently suffering from the consequences of massive overcapacity, resulting in unsustainable pressure on prices and profitability. Several private sector companies have, for some time now, been active in this industry, with many more expected to follow suit in the near future (Reinhard et $a l, 2000)$. In this environment, the only possible way to carry on is by cutting costs and increasing operational efficiency. It is therefore not only important but also critical to improve understanding of the concept of efficiency in the context of this specific sector. Definitions of efficiency measures, however, vary widely across industries because of the broad array of factors involved. The concept of efficiency should therefore be studied cautiously by considering the particular features and operational purposes of production units. Efficiency assessments of dry ports need to take into consideration both the intangible factors involved in the production process such as brand equity and customer satisfaction, as well as, of course, the tangible aspects such as container transportation and handling equipment; manpower deployed; and container throughput. In this vein, data envelopment analysis (DEA) is utilized here, to analyse productivity and performance of the dry ports located in the North Capital Region (NCR) of India during the period 2006-2009. In addition to the commonly considered outputs, such as container throughput, this article, for the first time in the port economics literature, also takes into consideration the 'negative' output of carbon emissions caused by port and transport activities.

A substantial body of research has been reported in the past decade on port productivity and efficiency assessments and benchmarking (for a good review, see Haralambides et al, 2010). Among them, Tongzon (2001); Hidekazu (2002) and Cullinane and Wang (2006) have applied DEA models to assess the efficiency of container terminals. Roy and Yvrande-Billon (2007) have investigated the impact of ownership structures on technical efficiency in the urban public transport sector. The results corroborate the frequently propounded assumption that technical efficiency depends on the ownership regime of the inputs deployed in the production process. In the case of ports, in particular, such inputs concern the provision of infrastructure; cargo-handling equipment; nautical services and port labor in general. Growitsch and Wetzel (2009) have conducted a pan-European efficiency analysis to investigate the performance of European railways. They conclude that undesirable outputs, such as environmental impacts, do adversely affect operational efficiency.

Terminal productivity studies, especially those concerned with the measurement of technical efficiency in container handling operations, mainly adopt

\footnotetext{
(C) 2012 Macmillan Publishers Ltd. 1479-2931 Maritime Economics \& Logistics Vol. 14, 1, 122-137 123
} 
container throughput as the single output variable. In this way, higher levels of container throughput will indicate greater levels of efficiency, with the same amount of inputs. Nowadays, however, this approach may be questioned, in view of the adverse environmental impacts of port operations and related transport systems. The efficiency scores computed in the current article explore what might be called the socially efficient operational performance of dry ports, by considering both outputs; that is, container throughput along with its conjoined and incidental twin, that is $\mathrm{CO}_{2}$ emitted by the decision-making unit (DMU), either directly (because of its own operations) or indirectly (as a result of the operations of inputs used -in this case, rail transport to/from dry ports). Furthermore, the article takes into consideration the fundamental characteristics of the dry port industry, looking at it essentially as an integrated transport industry using multiple modes of transport to carry containers between gateway ports and the country's hinterland. The $\mathrm{CO}_{2}$ emissions of dry ports are quantified, based on established global norms such as emissions per ton-mile of rail transport (Agarwal and Gupta, 2009).

The NCR dry ports play a key role in the supply chain of the country's international trade by acting as nodal points of cargo-consolidation and distribution, and by providing connectivity to gateway seaports. However, before addressing the efficiency of dry ports, it is essential to first define the pertinent inputs and outputs of the dry port service. It is also necessary to understand and explore, in the proper perspective, the fluctuations in efficiency estimates of dry ports, vis-à-vis variations in output and in the constituent input factors. Adding to existing literature, this article endeavours to ascertain the relevance of conventional efficiency estimates, when one incorporates negative environmental externalities. The methodology proposed here can be easily transferred to any other industrial sector where environmental concerns are becoming an issue.

Recent studies on environmental impact assessment and the ensuing policy changes are urging logistics service providers and port operators to re-evaluate and re-calibrate their roles and responsibilities in protecting the natural environment. Various management systems have at the same time been developed to evaluate the environmental impact of container transportation processes. In spite of this, $\mathrm{CO}_{2}$ emissions during the transportation process have not been considered to be of particular importance until very recently. However, under the present circumstances, this state of affairs is unlikely to continue for long. One way to gain insights into the environmental impacts of a production process is to analyse its eco-efficiency. In this article, we attempt to define ecoefficiency as a measure which also takes into consideration the undesirable outputs of the DMU, in this case $\mathrm{CO}_{2}$ emissions.

DEA is a well-established methodology for assessing the efficiency of organizations with the same set of inputs and outputs. In recent years, conventional 
DEA methods have been extended to also measure eco-efficiency by including undesirable outputs. Such models are often called eco-DEA or environmental DEA models. As pointed out by Dyckhoff and Allen (2001), it is no longer appropriate to solely embrace the assumptions of the traditional DEA model: that is, maximizing the quantity of outputs, while minimizing the amount of inputs to achieve higher efficiency. Thus, new approaches have been proposed, incorporating undesirable outputs in the DEA framework.

For the purpose of this study, we collect data by conducting personal interviews with 16 dry port managers located in the North Central Region of India. Nine of the 16 dry ports are managed by private operators, whereas the remaining seven dry ports are under public administration. The container handling equipment deployed at each dry port, the number of employees and the terminal area are considered as inputs here, whereas the annual throughput and the total $\mathrm{CO}_{2}$ emissions are considered as outputs. All seven public dry ports enjoy a comparative advantage over their private counterparts, in that they possess their own rail heads located on their own premises; only three of the privately operated dry ports have this facility. The rest have to transport their containers by truck to the nearest rail head, resulting in additional generalized costs. Thus, the size of the dry port becomes an important input, as a dedicated rail head necessitates a larger area.

The next section provides the research background of this article, through a review of the major relevant literature. It is followed by the next section, which is a conceptual buildup and explanation of desirable and undesirable outputs, and the validation of the model for the quantification of the dry port production output. The subsequent section is an exposition of the DEA methodology employed in this article. The next section specifies input and output indices utilized in the model that are developed specifically for the achievement of the article's stated objective. This section also explains the nature and sources of the data collected for this study. The results of the data analysis are presented in the penultimate section. The results of the analytical exercise, along with conclusions and implications, are presented in the final section.

\section{Research Background}

With the development of global multimodal supply chains, dry ports have assumed increasing importance in facilitating market development, seamless integration and closer collaboration between the different stakeholders in the supply chain and of transport networks. It was thus a logical step, by many gateway ports, to integrate upstream and extend their services to locations

\footnotetext{
(C) 2012 Macmillan Publishers Ltd. 1479-2931 Maritime Economics \& Logistics Vol. 14, 1, $122-137125$
} 
situated further hinterland. This was done by either forming strategic alliances or buying out existing dry ports so as to increase the reliability of their supply chains. The establishment of the NCR dry ports allowed shippers to undertake consolidation and distribution activities at inland locations closer to their production facilities, resulting in the reduction of transportation costs and accompanying risks, as well as their products becoming competitive in global markets.

Towards the end of 2008, over 200 dry ports, both private and public, had been established throughout India, with over 30 in the NCR region alone. Apart from the conventional functions described earlier, dry ports in India are also perceived as catalysts in promoting regional economic development (van den Bossche and Gujar, 2010). As a consequence, the government has been promoting the establishment of dry ports, especially by the private sector. Another reason for the rapid growth of this sector has been the creation of Special Economic Zones throughout the country and the simplification of customs procedures, notably digital documentation. Further developments in road, rail and port infrastructure, by way of capacity augmentation and automation, is expected to assist in the realization of the true potential of containerization in India, which is anticipated to treble in the next decade. The hinterland of gateway ports for container traffic is estimated to increase to 70 per cent from its current 35 per cent level (Dayal, 2006).

The contemporary global economy is characterized by increasing consumption of goods and services that can be produced at distant locations. This has also facilitated the opening up of global consumer markets to India. As such, being the inland logistics nodes of supply chains, the efficiency of dry ports becomes pivotal in complementing the changing role of ocean carriers and other stakeholders along the supply chain (Heaver, 2002; Sánchez et al, 2003; Notteboom and Rodrigue, 2005).

Next to, and as a result of, the intense competition that characterizes the Indian dry port industry today, the interests of the Indian policymakers have also been drawn to questions regarding the efficiency with which resources are utilized and their impact on the environment. Thus, the analysis of the performance of individual dry ports assumes greater significance for the success of the supply chain as a whole (Haralambides and Behrens, 2000). It is obvious, however, that a dichotomous dilemma exists between increasing dry port throughput on the one hand, and containing carbon emissions on the other. In other words, the greater the number of TEUs handled and transported over longer distances within shorter time periods, the greater the environmental impact and the higher the transaction costs.

The article also illustrates a common finding, encountered in many existing approaches to dealing with undesirable outputs in DEA (Tongzon, 
2001): When an undesirable output, such as pollution, is simply incorporated into a DEA model, the eco-DEA model gives higher, instead of lower, efficiency scores. This is a problem that needs to be corrected, and the undesirable output properly isolated, so that its impact can be quantified in the overall efficiency score. The existing literature fails to address undesirable outputs in this light.

We summarize below the five alternatives available to the dry port operator, before conducting DEA efficiency analysis.

1. Ignoring undesirable outputs: This refers to the traditional DEA model which neglects undesirable outputs (Nakashima et al, 2006; Lu and Lo, 2007a, b). However, nowadays it is not only inappropriate to ignore the presence of $\mathrm{CO}_{2}$ emissions during transportation, but this could result in erroneous decisions, since undesirable and desirable outputs are produced at the same time. As the undesirable output is of a different, that is 'negative', nature, it should be clearly distinguished in modelling the problem.

2. Treating undesirable effects as inputs (costs): Dyckhoff and Allen (2001) consider DEA as a multicriteria approach, modelling the undesirable output as an input. The model is applied to measure the environmental efficiency of the Dutch dairy farms (Reinhard et al, 2000), and compare it against the permissible quota of $\mathrm{CO}_{2}$ emissions stipulated in the Kyoto Protocol (Paul, 2005). However, as regards Indian dry ports, treating undesirable outputs as inputs fails to reflect true production. Also, the present regulations do not impose a penalty to encourage the minimization of carbon emissions by way of a carbon tax or usage of better fuels. In general, there is a lack of political will to implement suitable policies to reduce carbon emissions. Hence, it is difficult to consider carbon emissions as an input which the dry port operator would naturally try to minimize in an effort to improve operational efficiency. On the contrary, when a dry port tries to improve efficiency by increasing throughput, it is also increasing the quantity of emitted $\mathrm{CO}_{2}$.

3. Non-linear monotonic decreasing transformation approach: This data transformation approach is suggested by Golany and Roll (1989). It converts an 'undesirable' output into a 'normal' or 'desirable' output by a monotonically decreasing function $f$ of the form: $f\left(u_{i}^{k}\right)=1 / u_{i}^{k}$, where $u_{i}^{k}$ is the $i$ th element of the vector $u$ of undesirable outputs of DMU $k$. In such a manner, performance would be inversely related to the undesirable output. Lovell et al (1995) compare the macroeconomic performance of 19 OECD countries using the same approach: The reciprocals of undesirable outputs (carbon and nitrogen emissions) are treated as normal outputs.

4. Linear monotonic decreasing transformation: This approach has been suggested by Seiford and Zhu (2002). Here, the data transformation is given 
by $f\left(u_{i}^{k}\right)=-u_{i}^{k}+\beta_{i}$, where $\beta_{i}$ is a sufficiently large positive scalar. Lu and Lo (2007b) utilized this model to examine the overall performance of different regions in China, based on economic and environmental factors. In their analysis, the desirable output under consideration was GDP and the undesirable outputs were emissions such as soot, dust and sulphur dioxide. This model has been criticized for its invariance to data transformation within the DEA model (Lu and Lo, 2007a, b).

5. Treating undesirable factors in non-linear DEA models: This approach is based on the non-linear DEA model suggested by Färe et al (2004). The model builds on the weak disposability of undesirable outputs theory of Zhou et al (2007). Weak disposability assumes that it might be too costly to reduce undesirable outputs because, at the same time, this increases inputs (costs) or decreases desirable outputs (Yang and Politt, 2010). Therefore, this approach models the undesirable output as a 'normal' output and then adjusts by optimizing the distance measurement of the undesirable output (Liu, 1995). The model tends to increase the desirable and undesirable outputs at the same time. The weak disposable reference technology is also referred to as the environmental DEA technology (Färe et al, 2004; Zhou et al, 2007; Zhou et al, 2008). This model has been applied by Färe et al (1996) to compare the environmental performance of US fossil-fuel-fired electric utilities, incorporating an aggregate undesirable output of global annual emissions of $\mathrm{SO}_{2}, \mathrm{NO}_{2}$ and $\mathrm{CO}_{2}$. Yörük and Zaim (2008) employed the above framework to construct a performance index to evaluate the environmental performance of 28 OECD countries.

\section{Research Design}

In recent years, the issue of climate change has grabbed the attention of policymakers at an astonishing rate. Widespread acceptance of the basic science of climate change and recognition of the potential threat that it poses to our ecosystems and way of life has made the pursuit of $\mathrm{CO}_{2}$ reductions a major priority for all concerned.

This article takes into consideration the results of a macrolevel analysis of $\mathrm{CO}_{2}$ emissions, undertaken by the Indian Government, with regard to domestic freight transport. In the absence of a robust methodology and reliable data for computing the quantity of $\mathrm{CO}_{2}$ emitted per ton-kilometer of cargo transported and handled by dry ports, crude estimates had to be considered, often involving extrapolation from research done in foreign countries, especially western European. However, necessary diligence has been exercised 
while making computations. The following factors have been taken into consideration:

1. Fuel consumption is assumed to be proportional to load factors. A 90 per cent load factor has been considered for rail wagon utilization and 70 per cent in terms of weight utilization (UNESCAP, 2008). We have also taken into account the demand imbalance that exists to and from the dry ports. This results in a 10 per cent empty wagon movement. The imbalance problem has been further aggravated in the recent past because of the additional wagons introduced by private operators and the almost simultaneous fall in traffic (UNCTAD, 2009).

2. We have assumed each loaded TEU to have an average weight of 12 metric tons (70 per cent of maximum gross weight). According to our data, 10 per cent of the containers transported to and from the NCR dry ports are empty. The average gross weight of a container is 18 metric tons (the maximum permissible weight is 24 metric tons).

3. Considering the fact that containers from NCR dry ports are destined for Jawaharlal Nehru Port Trust (JNPT) (80 per cent), Mundra (15 per cent) and Chennai ( 5 per cent), we have assumed an average distance to gateway port of $1000 \mathrm{kms}$, which corresponds to 12000 ton-kms per TEU.

4. Analyses of the carbon intensity of freight transport invariably express $\mathrm{CO}_{2}$ emissions in terms of ton-kms, that is, average weight of container transported multiplied by the average distance travelled.

Calculations of $\mathrm{CO}_{2}$ emissions are derived from estimates of the actual amount of cargo transported and the energy consumed per unit of output. The 'output' of freight transport operations is generally measured by ton-kms and energy consumption by liters of fuel or kilowatt-hours of electricity used per ton-km. The latter is based on extensive surveys conducted on freight transport operators. Such a 'bottom-up' system of measurement is generally acknowledged to provide accurate estimates of $\mathrm{CO}_{2}$ emissions. On the basis of generally accepted international estimates (Seiford and Zhu, 2002) we have assumed an average carbon emission estimate of $40 \mathrm{gm} / \mathrm{ton}-\mathrm{km}$ for container rail transportation (Lan and Lin, 2006).

Containers moved on the rail network of India are hauled by diesel locomotives. Previous studies have indicated that $\mathrm{CO}_{2}$ emissions per ton-km are significantly lower for electric traction (Anand et al, 2005). However, as a result of capacity and cost constraints in the electrified tracks, electric traction is exclusively used for passenger traffic.

Fuel consumption data was obtained from CONCOR, a large rail freight operator. Ton-kms were multiplied by estimates of fuel consumption per ton-km, 
Table 1: Data of 16 DMUs

\begin{tabular}{|c|c|c|c|c|c|c|c|}
\hline Dry port & Equipment & Employees & $\begin{array}{c}\text { Area } \\
\left({ }^{\prime} 000 \mathrm{~m}^{2}\right)\end{array}$ & $\begin{array}{l}\text { Throughput } \\
\text { '000 TEU (T) }\end{array}$ & $\begin{array}{c}\text { Weight } \\
(M)=(T \times 12) \\
\text { '000 MT }\end{array}$ & $\begin{array}{c}\text { Distance } \\
(C)=(M) \times 1000 \\
\text { million } M T-k m\end{array}$ & $\begin{array}{c}\text { Emissions - } \\
(E)=(C) \times 0.00004 \\
\\
000 \mathrm{MT}\end{array}$ \\
\hline 1 & 4 & 22 & 50 & 21.34 & 277.4 & 277485 & 11.09 \\
\hline 2 & 4 & 26 & 50 & 26.75 & 347.8 & 347802 & 13.91 \\
\hline 3 & 4 & 30 & 50 & 28.73 & 373.5 & 373503 & 14.94 \\
\hline 4 & 4 & 24 & 50 & 24.89 & 323.5 & 323583 & 12.94 \\
\hline 5 & 4 & 25 & 50 & 31.25 & 406.3 & 406302 & 16.25 \\
\hline 6 & 4 & 28 & 50 & 31.98 & 415.8 & 415818 & 16.63 \\
\hline 7 & 1 & 19 & 50 & 31.27 & 406.5 & 406588 & 16.26 \\
\hline 8 & 1 & 28 & 50 & 48.96 & 636.5 & 636545 & 25.46 \\
\hline 9 & 8 & 32 & 50 & 156.71 & 2037.2 & 2037000 & 81.48 \\
\hline 10 & 7 & 36 & 150 & 145.76 & 1894.9 & 1895000 & 75.79 \\
\hline 11 & 4 & 14 & 160 & 168.54 & 2191.0 & 2191000 & 87.64 \\
\hline 12 & 5 & 27 & 68 & 82.34 & 1070.4 & 1070000 & 42.81 \\
\hline 13 & 2 & 17 & 80 & 74.39 & 967.1 & 967174 & 38.68 \\
\hline 14 & 1 & 12 & 24 & 16.76 & 217.9 & 217932 & 8.71 \\
\hline 15 & 2 & 14 & 53 & 13.23 & 172.0 & 172029 & 6.88 \\
\hline 16 & 32 & 84 & 36 & 432.98 & 5628.8 & 5629000 & 225.15 \\
\hline
\end{tabular}

and a $\mathrm{CO}_{2}$ conversion ratio for gas oil (Table 1). The calculation also took into account differences in fuel consumption between loaded and empty container haul operations (UNESCAP, 2008).

\section{Comparison of DEA Models}

DEA is a non-parametric linear programming technique for assessing the efficiency of a facility, or a profit centre, usually called a 'DMU' (in this case a dry port). From a given set of DMUs, the DEA technique constructs an empirical production frontier representing the most efficient production technology, given factor endowments. The relative performance of an individual DMU is evaluated (benchmarked) by comparing it to the most efficient unit, located on the frontier. The performance measurement is expressed in the form of an efficiency score. This comparison reveals the changes in inputs and outputs, necessary for the individual DMU in order to reach the production frontier (Banker et al, 1984)

In comparison to other techniques of efficiency evaluation, the DEA methodology has significant advantages as it can handle multiple inputs and outputs without the need to postulate a certain production function specification. The model selected for the current article is essentially a multiple outputoriented one, attempting to simultaneously maximize throughput and minimize carbon emissions, while retaining the same tangible inputs, that is number of container handling equipment, manpower deployed and surface area. 
Assuming there are $n \operatorname{DMU}_{j}(j=1, \ldots, n)$ and they use $k$ inputs $x_{i j}(i=1$, $\ldots, k)$ to produce $s$ outputs $Y_{r j}(r=1, \ldots, s)$, the DEA-CCR model computes the relative efficiency score of $D M U_{j}$ by maximizing:

$$
\operatorname{Max} \sum_{r=1}^{s} u_{r} y_{r m}=\theta_{m}
$$

Subject to

$$
\begin{gathered}
\sum_{i=1}^{k} v_{i} x_{i m}=1 \\
\sum_{r=1}^{s} u_{r} y_{r j}-\sum_{i=1}^{k} v_{i} x_{i j} \leqslant 0, \quad j=1, \ldots, n, \\
u_{r} \geqslant 0, \quad r=1, \ldots, s, \\
v_{i} \geqslant 0, \quad i=1, \ldots, k,
\end{gathered}
$$

where $v_{i}$ and $u_{r}$ are the unknown input and output weights, and $x_{i m}$ and $y_{r m}$ are the observed input and output values of $D M U_{m}$ (the DMU to be evaluated). The target is to obtain those weights $u_{r}$ and $v_{i}$ that maximize the efficiency score of $D M U_{j}$. The values of $\theta_{m}$ are the scores of $D M U_{m}$, relative to all $D M U$, and range between 0 and 1 . A $D M U$ is technically efficient if $\theta_{m}=1$, otherwise it is technically inefficient.

Consider now the dual problem to this, and let $\varphi$ and $\lambda_{j}(j=1, \ldots, n)$ be the dual variables. The above model can be reformulated as:

\section{$\operatorname{Min} \varphi$}

Subject to

$$
\begin{gathered}
\sum_{j=1}^{n} \lambda_{j} x_{i j} \leqslant \varphi x_{i m}, \quad i=1, \ldots, k \\
\sum_{j=1}^{n} \lambda_{j} y_{r j} \geqslant y_{r m}, \quad r=1, \ldots, s \\
\lambda_{j} \geqslant 0, \quad j=1, \ldots, n
\end{gathered}
$$

The addition of the convexity constraint $\sum_{j=1}^{n} \lambda_{j}=1$ to the above formulation constitutes what is known as the DEA-BCC model (constant returns to scale). 
The output-oriented measure of technical efficiency of $D M U_{m}$ is given by:

$$
T E=\frac{1}{\varphi}
$$

The efficiency score of $D M U_{m}$ is given by:

$$
S E=\frac{T E_{-} C C R}{T E_{B C C}}
$$

By using data collected from the NCR depots (Container Corporation of India, 2010), we review the eco-DEA models discussed in the previous section.

Table 1 gives the data of the 16 DMUs, with three inputs and two outputs, one of which is undesirable (emissions). DEAP 2.1 is used to run the models. The study assumes variable returns to scale.

Finding 1: The existing approaches tend to increase efficiency scores.

According to Table 2, when method 1 is compared with other approaches, the efficiency scores are fairly similar. In general, the number of efficient DMUs and the mean efficiency score under methods 2, 3 and 4 are similar. However, there is a small increase in the efficiency ratios.

Finding 2: The undesirable output can either have a positive or negative effect on the efficiency score.

From Table 2, it can be seen that after incorporating the undesirable output, the results are altered. However, this change fails to explain the presence of undesirable output. In fact, the efficiency score should change in a manner which unambiguously reflects the presence of the undesirable output. For example, the desirable output of dry port A is greater than dry port B. However, when accommodating the carbon emissions generated by both dry ports, dry port $\mathrm{B}$ generates less $\mathrm{CO}_{2}$ than dry port A. Taking into consideration both these aspects for comparison, dry port $\mathrm{B}$ behaves better in the environmental aspect because it produces less $\mathrm{CO}_{2}$ per unit of desirable output. Therefore, dry port $\mathrm{B}$ can be regarded as more environmentally efficient compared with dry port A (Nakashima et al, 2006).

\section{The Eco-DEA Model}

As explained in the previous section, existing methods fail to accommodate the adverse effects of the eco-variables viz; $\mathrm{CO}_{2}$ emissions, in the DEA model. In this section, we propose a new approach to deal with undesirable outputs. 
Table 2: Results of DMU efficiency scores for methods 1-4

\begin{tabular}{lcccc}
\hline DMU & Method 1 & Method 2 & Method 3 & Method 4 \\
\hline 1 & 0.224 & 1.000 & 0.481 & 0.554 \\
2 & 0.281 & 1.000 & 0.411 & 0.522 \\
3 & 0.302 & 1.000 & 0.399 & 0.530 \\
4 & 0.262 & 1.000 & 0.438 & 0.539 \\
5 & 0.329 & 1.000 & 0.424 & 0.556 \\
6 & 0.336 & 1.000 & 0.414 & 0.542 \\
7 & 0.673 & 1.000 & 0.903 & 1.000 \\
8 & 1.000 & 1.000 & 1.000 & 1.000 \\
9 & 1.000 & 1.000 & 1.000 & 1.000 \\
10 & 0.638 & 0.864 & 0.638 & 0.638 \\
11 & 1.000 & 1.000 & 1.000 & 1.000 \\
12 & 0.672 & 1.000 & 0.684 & 0.732 \\
13 & 0.882 & 1.000 & 0.896 & 0.986 \\
14 & 0.529 & 1.000 & 1.000 & 1.000 \\
15 & 0.198 & 1.000 & 1.000 & 0.864 \\
16 & 0.229 & 0.307 & 0.229 & 0.229 \\
Mean & & & & 0.735 \\
No. of efficient DMUs & 0.539 & 0.957 & 0.686 & 5 \\
\hline
\end{tabular}

This method takes into account the impact rate of the undesirable output on the efficiency score. Accordingly, the intensity of the impact, or the influence of the undesirable output, is considered as a negative output that leads to a decrease in efficiency scores. The whole idea can be expressed as follows:

$$
\begin{aligned}
& C=(B-A) \\
& A^{*}=A(1-C)
\end{aligned}
$$

$A$ represents the efficiency score obtained by the conventional DEA model without considering the undesirable output. $B$ refers to the efficiency score obtained by the conventional DEA model with the incorporation of undesirable output. The undesirable output is treated in the same way as the desirable output. $C$ denotes the environmental impact brought by the undesirable output where $0 \leqslant C \leqslant 1$. The value of $(1-C)$ implies the proportion of reduction in $A$ when undesirable output is included. Following this logic, $A^{*}$ represents the efficiency score which accounts for the impact of the undesirable output brought to the original efficiency score $A$.

As seen in Table 3 , the values of $C$ are equivalent to the impact brought about by the undesirable output. For example, under the impact rate method (Tongzon, 2001), the efficiency scores of the DMUs drop significantly. The present approach of solving DEA models with undesirable outputs is more advanced than the previous methods seen in the literature. The effect of the

\footnotetext{
(C) 2012 Macmillan Publishers Ltd. 1479-2931 Maritime Economics \& Logistics Vol. 14, 1, $122-137133$
} 
Table 3: Results of efficiency scores under the impact rate method

\begin{tabular}{lcccc}
\hline DMUs & $A$ & $B$ & $C$ & $A^{*}$ \\
\hline 1 & 0.224 & 0.224 & 0.000 & 0.224 \\
2 & 0.281 & 0.281 & 0.000 & 0.281 \\
3 & 0.302 & 0.302 & 0.000 & 0.302 \\
4 & 0.262 & 0.262 & 0.000 & 0.262 \\
5 & 0.329 & 0.329 & 0.000 & 0.329 \\
6 & 0.336 & 0.336 & 0.000 & 0.336 \\
7 & 0.673 & 0.673 & 0.000 & 0.673 \\
8 & 1.000 & 1.000 & 0.000 & 1.000 \\
9 & 1.000 & 1.000 & 0.000 & 0.493 \\
10 & 0.638 & 0.864 & 0.226 & 1.000 \\
11 & 1.000 & 1.000 & 0.000 & 0.672 \\
12 & 0.672 & 0.672 & 0.000 & 0.882 \\
13 & 0.882 & 0.882 & 0.000 & 0.529 \\
14 & 0.529 & 0.529 & 0.000 & 0.198 \\
15 & 0.198 & 0.198 & 0.000 & 0.110 \\
16 & 0.229 & 0.747 & 0.518 & 3 \\
No. of efficient DMUs & 3 & 3 & 0 & \\
\hline
\end{tabular}

undesirable output is considered as negative and the efficiency score takes this factor into account. Thus, the impact rate method 'transforms' the undesirable output from a new perspective.

The undesirable output could also be converted into a ratio form, by comparing it with the desirable output. In this manner, the undesirable aspects of the outputs can be eliminated altogether.

\section{Empirical Analysis and Discussions}

As can be seen from Table 4, the efficiency of all except three dry ports varies under different methods. Dry port 16 is the largest in the region with the highest throughput. It also has the highest labour force and equipment deployed. Furthermore, the number of efficient dry ports is the highest according to the second method. This is an anomaly owing to the fact that carbon emissions are not taxed and, as such, do not constitute a cost for the operator.

Every dry port has its own strengths and weaknesses, on the basis of which they develop their own strategic business plans. In the current environmental situation, however, the pursuance of strategic objectives - that is, cost minimization and/or product differentiation - cannot be unconstrained: they ought to be pursued with an eye to minimizing environmental impact. This is particularly the case for privately owned and managed dry ports which are completely focused on maximizing profits while simultaneously minimizing 
Table 4: Comparative efficiency scores of 16 DMUs derived by different methods

\begin{tabular}{lccccc}
\hline DMU & Method 1 & Method 2 & Method 3 & Method 4 & Method 5 \\
\hline 1 & 0.224 & 1.000 & 0.481 & 0.554 & 0.224 \\
2 & 0.281 & 1.000 & 0.411 & 0.522 & 0.281 \\
3 & 0.302 & 1.000 & 0.399 & 0.530 & 0.302 \\
4 & 0.262 & 1.000 & 0.438 & 0.539 & 0.262 \\
5 & 0.329 & 1.000 & 0.424 & 0.556 & 0.329 \\
6 & 0.336 & 1.000 & 0.414 & 0.542 & 0.336 \\
7 & 0.673 & 1.000 & 0.903 & 1.000 & 0.673 \\
8 & 1.000 & 1.000 & 1.000 & 1.000 & 1.000 \\
9 & 1.000 & 1.000 & 1.000 & 1.000 & 1.000 \\
10 & 0.638 & 0.864 & 0.638 & 0.638 & 0.668 \\
11 & 1.000 & 1.000 & 1.000 & 1.000 & 1.000 \\
12 & 0.672 & 1.000 & 0.684 & 0.732 & 0.672 \\
13 & 0.882 & 1.000 & 0.896 & 0.986 & 0.882 \\
14 & 0.529 & 1.000 & 1.000 & 1.000 & 0.529 \\
15 & 0.198 & 1.000 & 1.000 & 0.864 & 0.198 \\
16 & 0.229 & 0.307 & 0.229 & 0.229 & 0.110 \\
& & & & 0.735 & 0.531 \\
Mean & 0.539 & 0.957 & 0.686 & 5 & 3 \\
No. of efficient DMUs & 3 & 14 & 5 & & 5 \\
\hline
\end{tabular}

transaction costs (UNESCAP, 2006). It is, however, the public sector that should set the example. Public sector operated dry ports have an altogether different focus which is rather broad. The focus in this case is more aligned with the government's macroeconomic policies where financial results have a comparatively lower priority, compared to the provision of services to trade as a whole. Furthermore, environmental issues are accorded a lower priority vis-à-vis the growth of international trade. At present, public sector dry ports completely ignore $\mathrm{CO}_{2}$ emission impacts.

\section{Conclusions}

Different methods to incorporate the undesirable aspects of dry port service production into DEA models are discussed and compared in this article. However, these methodologies tend to give the dry port a better efficiency score after taking undesirable factors into consideration and this does not allow operators and policymakers to single out environmental effects and act upon them.

To address this issue, the model presented here, in addition to simultaneously dealing with both desirable and undesirable outputs, adjusts dry port efficiency scores and the number of efficient DMUs. In this way, a better balance can be achieved between production and its negative externalities. 
Finally, although the model is applied to the dry port sector of India, its generality allows its straightforward application to any other industrial or service sector of the economy where environmental impacts and other externalities are issues of concern.

\section{References}

Agarwal, V.K. and Gupta, A.K. (2009) Transportation scenario 2030 and environmental impact. Rites Journal 11: 8.0-8.10.

Anand, S., Vrat, P. and Dahiya, R.P. (2005) Application of system dynamics approach for assessment and Mitigation of $\mathrm{CO}_{2}$ emissions. Journal of Environmental Management, doi: 10.1016/ j.jenvman.2005.08.007.

Banker, R.D., Charnes, A. and Cooper, W.W. (1984) Some models for estimating technical and scale efficiencies in data envelopment analysis. Management Science 30: 1078-1092.

Container Corporation of India. (2010) http://www.concorindia.com, accessed July 2010.

Cullinane, K.P.B. and Wang, T.F. (2006) The efficiency of European container ports: A cross sectional data envelopment analysis. International Journal of Logistics: Research and Application 9(1): 19-31.

Dayal, R. (2006) Promoting Dry Ports as a Means of Sharing the Benefits of Globalization with Inland Locations. Bangkok: UNESCAP Committee on Managing Globalization, E/ESCAP/CMG (3/1), 1.

Dyckhoff, H. and Allen, K. (2001) Measuring ecological efficiency with data envelopment analysis (DEA). European Journal of Operational Research 132: 312-325.

Färe, R., Grosskopf, S. and Hernanadez-Sancho, F. (2004) Environmental performance: An index number approach. Resource and Energy Economics 26: 343-352.

Färe, R., Grosskopf, S. and Tyteca, D. (1996) An activity analysis model of the environmental performance of firms - Application to fossil-fuel-fired electric utilities. Ecological Economics 18(2): 161-175.

Golany, B. and Roll, Y. (1989) An application procedure for DEA. Omega 17: 237-250.

Growitsch, C. and Wetzel, H. (2009) Testing for economies of scope in European railways: An efficiency analysis. Journal of Transport Economics and Policy 43(1): 1-24.

Haralambides, H.E. and Behrens, R. (2000) Port restructuring in a global economy: An Indian perspective. International Journal of Transport Economics XXXVII(1): 19-39.

Haralambides, H.E., Hussain, M., Pestana-Barros, C. and Peypoch, N. (2010) A New approach in benchmarking seaport efficiency and technological change. International Journal of Transport Economics 38(1): 77-96.

Heaver, T. (2002) The evolving role of shipping lines in international logistics. International Journal of Maritime Economics 4: 210-230.

Hidekazu, I. (2002) Efficiency changes at major container ports in Japan: A window application of data envelopment analysis. Review of Urban \& Regional Development Studies 14(2): 133-152.

Lan, L.W. and Lin, E.T.J. (2006) Performance measurement for railway transport: Stochastic distance functions with inefficiency and Ineffectiveness effects. Journal of Transport Economics and Policy 40(3): 383-408.

Liu, Z. (1995) The comparative performance of public and private enterprises. Journal of Transport Economics 29: 263-274.

Lovell, C.A.K., Pastor, J.T. and Turner, J.A. (1995) Measuring macroeconomic performance in the OECD: A comparison of European and non-European countries. European Journal of Operational Research 87(3): 507-518.

Lu, W.-M. and Lo, S.-F. (2007a) A benchmark-learning roadmap for regional sustainable development in China. Journal of the Operational Research Society 58: 841-849.

136 (C) 2012 Macmillan Publishers Ltd. 1479-2931 Maritime Economics \& Logistics Vol. 14, 1, 122-137 
Lu, W.-M. and Lo, S.-F. (2007b) A closer look at the economic-environmental disparities for regional development in China. European Journal of Operational Research 183(2): 882-894.

Nakashima, K., Nose, T. and Kuriyama, S. (2006) A new approach to environmental-performance evaluation. International Journal of Production Research 44: 4137-4143.

Notteboom, T. and Rodrigue, J.P. (2005) Port regionalization: Towards a new phase in port development. Maritime Policy and Management 32(3): 297-313.

Paul, J. (2005) India and the global container ports. Maritime Economics and Logistics 7(2): 189-192.

Reinhard, S., Lovell, C.A.K. and Thijssen, G.J. (2000) Environmental efficiency with multiple environmental detrimental variables; estimated with SFA and DEA. European Journal of Operational Research 121: 287-303.

Roy, W. and Yvrande-Billon, A. (2007) Ownership, contractual practices and technical efficiency: The case of urban public transport in France. Journal of Transport Economics and Policy 41(2): 257-282.

Sánchez, R.J., Hoffmann, J., Micco, A., Pizzolitto, G.V., Sgut, M. and Wilmsmeier, G. (2003) Port efficiency and international trade: Port efficiency as a determinant of maritime transport costs. Maritime Economics and Logistics 5: 199-218.

Seiford, L.M. and Zhu, J. (2002) Modeling undesirable factors in efficiency evaluation. European Journal of Operational Research 142: 16-20.

Tongzon, J. (2001) Efficiency measurement of selected Australian and international ports using data envelopment analysis. Transportation Research Part A: Policy and Practice 35(2): 113-128.

UNCTAD. (2009) Review of Maritime Transport. Geneva: United Nations Conference on Trade and Development.

UNESCAP. (2006) Transport and Communications Bulletin on Asia and Pacific. Technical Bulletin no. 75, Energy Security \& Sustainable Development in Asia and the Pacific, pp. 56-68.

UNESCAP. (2008) Transport and Communications Bulletin on Asia and Pacific. Technical Bulletin no. 77, Container Transportation by Railways, pp. 102-109.

van den Bossche, M. and Gujar, G.C. (2010) Competition, excess capacity and pricing of dry ports in India; some policy implications. International Journal of Shipping and Transport Logistics 2: 151-167.

Yang, H. and Politt, M. (2010) The necessity of distinguishing weak and strong disposability among undesirable outputs in DEA: Environmental performance of Chinese coal fired plants. Energy Policy 38(8): 4440-4444.

Yörük, B.K. and Zaim, O. (2008) International regulations and environmental performance. Applied Economics 40: 807-822.

Zhou, P., Ang, B.W. and Poh, K.L. (2007) A mathematical programming approach to constructing composite indicators. Ecological Economics 62: 291-297.

Zhou, P., Ang, B. and Poh, K. (2008) A survey of data envelopment analysis in energy and environmental studies. European Journal of Operational Research 189: 1-18. 